Short Paper

\title{
Simultaneous Detection of Infectious Hematopoietic Necrosis Virus (IHNV) and Infectious Pancreatic Necrosis Virus (IPNV) by Reverse Transcription (RT)-Polymerase Chain Reaction (PCR)
}

\author{
Toko Yoshinaka, Mamoru Yoshimizu, and Yoshio Ezura \\ Laboratory of Microbiology, Faculty of Fisheries, Hokkaido University, Hakodate, 041-8611, Japan \\ (Received September 11, 1997)
}

Key words: IHNV, IPNV, RT-PCR

Multiple virus infections have recently been observed during routine examination of salmonid fish. ${ }^{1)}$ Infectious hematopoietic necrosis virus (IHNV) and infectious pancreatic necrosis virus (IPNV) are often isolated together or with other viruses, such as a herpes virus or a retro-like virus. $^{1,2)}$ In case of multiple virus infections, only the virus which replicates most efficiently will be detected. In these cases, other viruses may be detected only after neutralization of the original sample with specific antibody against the virus isolated primarily. Therefore, a rapid diagnosis is needed to detect multiple viruses in culture fluid. Serological tests are rapid but generally lack sensitivity of detection and repeated neutralization assays may be needed to identify the isolated viruses. Furthermore, if an antibody against the virus is not available, identification of the virus is difficult. The polymerase chain reaction (PCR) is a rapid and sensitive method for detecting viruses in infected cells, and assays for different viral agents may be performed at the same time. ${ }^{2,3)}$ In this paper, we describe simultaneous detection of IHNV (strain ChAb) and IPNV (strain VR299, West Buxton and Jasper) by reverse transcription (RT)-PCR assay.

IHNV (strain ChAb) was isolated in our laboratory from chum salmon Oncorhynchus keta in Hokkaido, Japan. IPNV (strain VR299) was provided by Dr. J. L. Fryer, Center for Salmon Disease Research, Oregon State University, OR, USA and the West Buxton and Jasper strains were provided by Dr. B. J. Hill of The Centre for Environment, Fisheries \& Aquaculture Science (CEFAS), UK. All viruses were propagated at $15^{\circ} \mathrm{C}$ in rainbow trout embryo cells (RTE-2). ${ }^{4)}$ Virus was harvested when the CPE was completed and stored at $-80^{\circ} \mathrm{C}$ until use. IPNV and IHNV RNA were extracted using a Sepa-Gene (Sanko Junyaku) RNA extraction kit. The extracted RNA pellet was used as PCR template. Conditions for RT-PCR of simultaneous detection were as follows: primers for IHNV were described by Yoshinaka et al. ${ }^{2)}$, and primers for IPNV were the P1 and II primers described by Lopez-lastra et $a l .{ }^{3)}$ The IHNV second primer ${ }^{2)}$ and IPNV P1 and II primers ${ }^{3)}$ were used to generate first-strand cDNA in a RTreaction mixture $(10 \mu l)$ containing $2.5 \mathrm{U}$ AMV reverse transcriptase XL (Life Science) 1.0 U RNase inhibitor (Takara), and $1.5 \mathrm{~mm}$ each of the 4 deoxynucleotide triphosphates in PCR buffer supplied with the Takara RTPCR kit. The reaction mixture was incubated for $30 \mathrm{~min}$ at

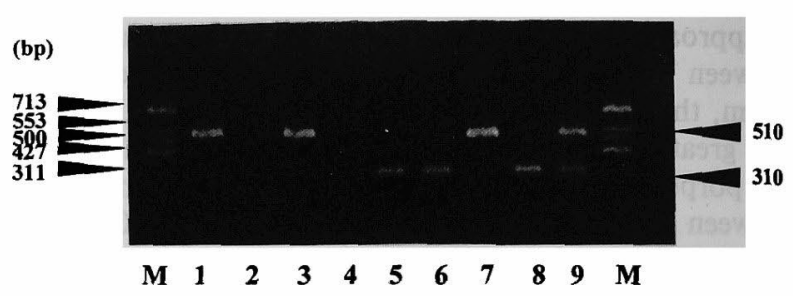

Fig. 1. Agarose gel electrophoresis of RT-PCR products of IHNV ChAb and/or IPNV VR299.

The gel was stained with ethidium bromide.

Lanes; M, DNA molecular weight markers.

Combinations of templates and primers are as follows: 1, IHNV and IHNV-primers. 2, IHNV and IPNV-primers. 3, IHNV and IHNV-primers and IPNV-primers. 4, IPNV and IHNV-primers. 5, IPNV and IPNV-primers. 6, IPNV and IHNV-primers and IPNVprimers. 7, IHNV and IPNV and IHNV-primers, 8, IHNV and IPNV and IPNV-primers. 9, IHNV and IPNV and IHNV-primers and IPNV-primers.

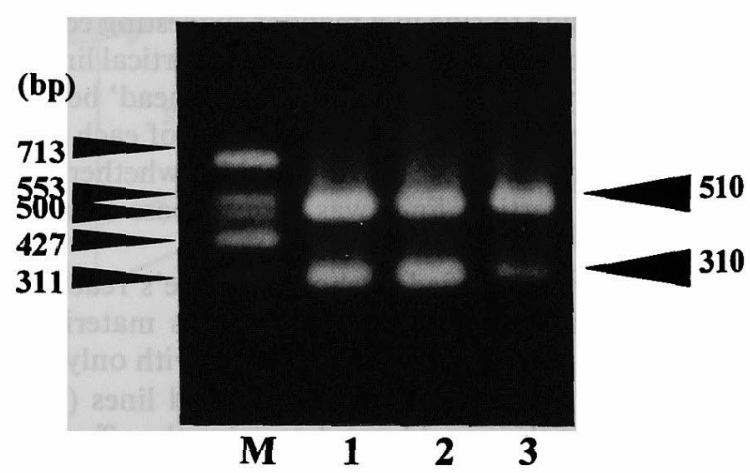

Fig. 2. Agarose gel electrophoresis of RT-PCR products of IHNV ChAb and IPNV West Buxton, Jasper, VR299.

The gel was stained with ethidium bromide.

Lanes; M, DNA molecular weight markers.

Combinations of templates were as follows: 1, IHNV ChAb and IPNV West Buxton. 2, IHNV ChAb and IPNV Jasper. 3, IHNV ChAb and IPNV VR299.

$45^{\circ} \mathrm{C}$. The cDNA was amplified by adding $3.3 \mathrm{U}$ of Taq DNA polymerase (Takara) and the IHNV first primer ${ }^{2)}$ to the reaction mixture. The PCR reaction was performed for 40 cycles in an automatic thermal cycler (Perkin Elmer Model 480) with each cycle consisting of $30 \mathrm{~s}$ at $94^{\circ} \mathrm{C}, 30 \mathrm{~s}$ 
at $44^{\circ} \mathrm{C}$ and $1 \mathrm{~min}$ at $72^{\circ} \mathrm{C}$. The amplified product was analyzed for purity and size by electrophoresis $(50 \mathrm{~V}, 1 \mathrm{~h})$ in $2 \%$ agarose gels.

Specificity of both primers was examined using a mixture of stock viruses of IHNV(ChAb) and IPNV(VR299) prepared as described above. Primer sets were confirmed to be specific for IHNV(ChAb) or IPNV(VR299) (Fig. 1). The detection limits for simultaneous use of RT-PCR for IHNV(ChAb) and IPNV(VR299) were $10^{3} \mathrm{TCID}_{50} / \mathrm{m} l$ and $10^{4} \mathrm{TCID}_{50} / \mathrm{m} l$, respectively (data not shown). Similarly, each of 3 IPNV strains VR299, West Buxton and Jasper could be detected identified simultaneous with separating with IHNV in a single RT-PCR (Fig. 2). These results indicate that both IHNV, which has single stranded RNA, and IPNV, which has double stranded RNA, could be in a single RT-PCR. When examining large numbers of ovarian fluid samples or routines to insure virus-free eggs, it is important to know quickly if IPNV or IHNV are present. Although the detection limits for simultaneous detection of virus are low, this method offers a rapid alternative to specific antibody for neutralization.

Acknowledgments We would like to express our sincere thanks to Dr. J. L. Bartholomew, Center for Salmon Disease Research, Oregon State University, OR, USA., for her critical reading of the paper and her valuable suggestions. This research was supported in part by a Grant-in-Aid for Scientific Research (B) No. 06454095 from the Ministry of Education.

\section{References}

1) Kumagai, A., K. Takahashi, and H. Fukuda: Fish Pathol., 32, 103108 (1997).

2) Yoshinaka, T., M. Yoshimizu, T. Sawabe, and Y. Ezura: Fisheries Sci., 63, 592-595 (1997).

3) Lopez-lastra, M., M. Gonzalez, M. Jashes, and A. M. Sandino: $J$. Fish Diseases., 17, 269-282 (1994).

4) Yoshinaka, T., M. Yoshimizu, and Y. Ezura: Fish Pathol., 32, 7580 (1997). 